Abstract\#: A-2021-RE100023

Tao Xingzhi Study Association of China \& Huzhou University

May 28-30, 2021, Huzhou, Zhejiang Province, China

The Projected Implementation of Human Geography on the basis of Practical Design: A Case Study of Taking a Map to the Journey

\title{
Dan Chen
}

Affiliation: Yuhuan Experimental School, Taizhou, Zhejiang, China 317600, China

Address: Yuhuan Experimental School, Taizhou, Zhejiang, China 317600, China

Correspondence to: Dan Chen, E-mail: $52932021 @ q q . c o m$

DOI: https://doi.org/10.15354/sief.21.s1.ab050

The authors declare no competing interest.

This paper begins with the quality analysis of the current project-based learning task of Humanities Geography, and further analyzes the "inauthenticity" and "insubstantiality" phenomenon in the process of project-based learning design, mainly in analyzing the problems of the entire process of determination of objectives, creation of situations, and design of driving tasks, implementation, presentation and evaluation of tasks. This paper chooses Taking a Map to the Journey as an example, which is the project task "the Application of Maps in Daily Life" in Humanities Geography, from the development of resources and determination of the theme to the creation of a realistic situation, from the design of higher-order thinking-driven "real" tasks to the organization and implementation of group "real" cooperation, and finally presents personalized achievement and designs the gauge to deepen the "real evaluation". By these means, the classroom project-based learning can be more effective and efficient and fully indicate the subject's core literacy, and thus realizing the "real design" of project-based learning.

\section{Keywords}

Humanities Geography, Project-Based Learning, Real Design

Science Insights Education Frontiers, 2021 September 13; Vol. 10, Suppl. 1, pp.20.

(c) 2021 Insights Publisher. All rights reserved.

Creative Commons Non Commercial CC BY-NC: This article is distributed under the terms of the Creative Commons Attribution-NonCommercial 4.0 License which permits non-commercial use, reproduction and distribution of the work without further permission provided the original work is attributed by the Insights Publisher. 